
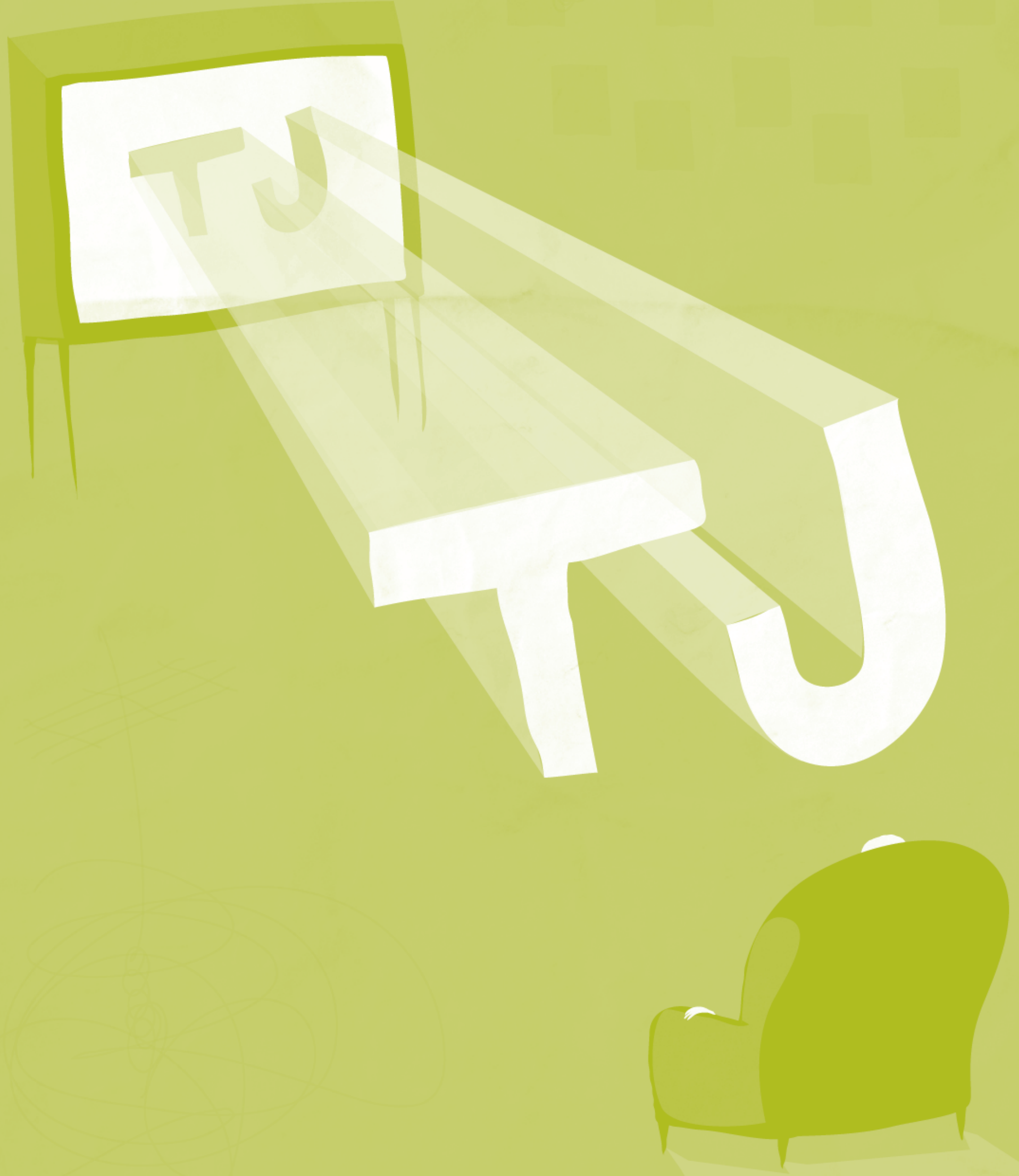


\section{Imagem: o papel da vinheta no estabelecimento da marca}

Jaqueline E. Schiavoni

- Mestranda do Programa de Pós-Graduação em Comunicação Midiática da Universidade Estadual Paulista (Unesp) e bolsista Fapesp

- Graduada em Comunicação Social com habilitação em Jornalismo pela Unesp

• jeschiavoni@yahoo.com.br 


\section{Resumo}

Este trabalho de pesquisa busca relacionar o conceito de marca com um tipo especial de produto audiovisual, o informativo televisivo. Consideraremos neste artigo três modos pelos quais as vinhetas de abertura de telejornais podem contribuir para o estabelecimento e fortalecimento das marcas em questão: os telejornais.

PALAVRAS-CHAVE: VINHETA • MARCA • IDENTIDADE • AUTO-REFERENCIALIDADE

\section{Abstract}

This survey seeks to relate the concept of brand with a special type of audio visual product, the television news program. In this article we will be considering three ways by which the opening vignettes of TV newscasts can contribute to establishing and strengthening the brands in question: the TV newscasts.

KEYWORDS: VIGNETTES • BRAND・IDENTITY • SELF-REFERENCE

\section{Resumen}

Este trabajo de investigación busca relacionar el concepto de marca con un tipo especial de producto audiovisual: el informativo televisivo. Consideraremos en este artículo tres modos por los cuales los titulares de los telediarios pueden contribuir al establecimiento y fortalecimiento de las marcas en cuestión: los telediarios.

PALABRAS CLAVE: TITULARES • MARCA • IDENTIDAD • AUTORREFERENCIALIDAD 
onceito. Idéia. Opinião. Representação. Todos esses termos podem nos vir à mente se pensamos em imagem. Alguém poderá dizer: "se eu me apresentar deste modo, que imagem farão de mim?" Mas a pergunta que pode, num primeiro momento, parecer ingênua ou melindrosa está longe de ocupar apenas esferas individuais, de natureza cotidiana, como ir a uma festa, apresentar-se para uma vaga de emprego ou comparecer a um jantar romântico.

Há muito tempo, esse tipo de pergunta permeia a produção dos mais variados tipos de indústrias - alimentícia, automotiva, têxtil, entre outras - e, principalmente, a divulgação de suas respectivas marcas e produtos. Afinal, dependendo do modo como nos apresentamos, podemos atrair ou repelir pessoas, conquistar ou fracassar em determinados objetivos e, no campo da produção em série, isso pode significar o ganho ou a perda de quantias que vão da casa do milhar aos milhões.

Neste artigo, abordaremos a questão da imagem, ou da construção da identidade, num tipo específico de indústria: a audiovisual. Quando a televisão se disseminou, carregou consigo três promessas ou funções básicas: entreter, educar e informar. Ao falarmos de vinheta, será sobre este último aspecto que nos debruçaremos de modo especial: a informação.

Com base nas vinhetas de abertura de telejornais da Rede Record de Televisão, Rede Bandeirantes de Televisão e Rede Globo de Televisão, demonstraremos três modos pelos quais as vinhetas podem contribuir para o estabelecimento e fortalecimento das marcas em questão: os informativos televisivos. Ao final do trabalho, abordaremos um pouco sobre o caráter auto-referencial da televisão, o papel das vinhetas na composição dessa estética e como as estratégias utilizadas nos breaks comerciais - envolvendo referencialidade e vinheta - são decisivas para gravar determinadas marcas na mente do consumidor-telespectador.

\section{Vinheta: estabelecendo a marca}

Para dar início ao desenvolvimento desse tema, vale a pena perguntar: o que é exatamente uma marca? Por que estabelecer uma marca forte é tão importante no caso do telejornalismo? De acordo com Tarsitano e Navacinsky,

"uma marca é um nome diferenciado e/ ou símbolo (tal como um logotipo, marca registrada ou desenho de embalagem) destinado a identificar os bens ou serviços de um ven- 
dedor ou de um grupo de vendedores e a diferenciar esses bens e serviços daqueles dos concorrentes. Assim, uma marca sinaliza ao consumidor a origem do produto e protege, tanto o consumidor quanto ofabricante, dos concorrentes que oferecem produtos que pareçam idênticos." (2004, p. 230)

Antes do advento do auto-serviço, muitos produtos não eram identificados; vendidos a granel, não era dada ao consumidor a opção de escolha, comprava-se o que se vendia. Se hoje há dezenas de marcas de um mesmo produto, a construção de marcas fortes parece ter sido um imperativo para a sobrevivência no mundo mercadológico.

Os telejornais, por sua vez, não escaparam a essa lógica mercantil e, como produtos midiáticos que são, buscaram estabelecer marcas suficientemente fortes para vender a si próprios.

Uma análise, mesmo que breve, dos telejornais veiculados atualmente pode revelar o processo de homogeneização a que estão submetidos. Não se trata apenas de questões estéticas tais como a disposição da bancada de apresentação, o enquadramento realizado, a vestimenta sóbria de seus apresentadores ou outras. Trata-se, também, de aspectos relacionados ao conteúdo dos programas.

A possibilidade de recorrer às mesmas agências de notícias, somada às facilidades proporcionadas pelas novas tecnologias - tanto para captação e transmissão de imagens como produção e veiculação "ao vivo" de conteúdos em qualquer parte do mundo - parece ter permitido o fim de maiores disparidades entre os telejornais. De modo que se pode observar uma correspondência tanto na estrutura dos programas (quanto às editorias: esporte, economia, internacional etc.) como também de notícias.

As diferenças que ainda podem ser sentidas variam de acordo com o horário em que os programas são veiculados. Os telejornais buscam construir as notícias visando ao público a que se destinam, conferindo para cada tipo de enunciatário (telespectador) uma abordagem particular do fato ${ }^{1}$.

Mesmo assim, a notícia não pode fugir de sua estrutura fundamental. Deve responder, em todos os casos, as perguntas do lead: O quê? Quem? Quando? Onde? Como? Por quê? E dessas perguntas, a única que sofre algum tipo de alteração de um telejornal para outro, na maioria dos casos, é "Por quê?". Em vista de diferenças tão estreitas que muitas vezes passam despercebidas pelo telespectador, o investimento em uma marca forte parece ter sido uma solução para escapar do processo de ho-

1 SCHIAVONI, J. E. Telejornal: recortando a notícia. In: XXVIII Congresso Brasileiro de Ciências da Comunicação - Intercom, 2005, Rio de Janeiro. Anais, Rio de Janeiro: Sonopress Ind. Com. Fonográfica Ltda., 2005. 1 CD ROM. 
mogeneização, na medida em que possibilita diferenciar o produto em relação aos concorrentes.

Mas isso não é tudo. A apresentação da marca também é capaz de assegurar qualidade e representar uma garantia para o consumidor. Essa garantia se dá: 1) à medida que o consumidor - da notícia, em nosso caso - consegue identificar a origem do produto que tem permitido entrar em sua casa; 2) ao conhecer um pouco mais sobre o conteúdo em questão e 3) por explorar determinadas figuras e temas, efetivando, baseado nisso, contratos de veridicção (dizer verdadeiro, fundamental para o telejornalismo) e fidúcia (crença, fé), imprescindíveis para estabelecer uma audiência cativa.

No caso dos telejornais, são as vinhetas que cumprem todos esses papéis. É, sobretudo, por intermédio desses videografismos que os telejornais se auto-apresentam (evidenciam sua origem e conteúdo) e passam a firmar contratos com o telespectador. Por isso, no decorrer deste trabalho, analisaremos três vinhetas que exemplificam cada um dos aspectos citados. Mas, antes disso, para compreendermos com mais clareza esse processo, vale a pena fazer um retrocesso na História e entender a utilização da vinheta como um artifício de ilustração e persuasão.

O termo "vinheta" nos remete à vinha, videira. Segundo Aznar, autor do livro Vinheta: do pergaminho ao vídeo, "a videira foi a forma utilizada para expressar todo o simbolismo do Antigo Testamento". Esse papel alegórico desempenhado pela videira foi amplamente divulgado pela igreja na Idade Média por meio da iluminura, a arte de "iluminar” os manuscritos da Bíblia. A iluminura funcionava como uma espécie de representação visual do texto, comportando ilustração, vinheta e caligrafia. Além de proporcionar certa medida de bem-estar visual, aquilo que as pessoas não pudessem entender pela escrita deveria ser aprendido por meio das figuras.

"A igreja Católica começou a utilizar a arte da iluminura no século IV, primeiramente em evangelhos, saltérios, livros de horas e Bíblias, com ofim de 'adornar, ilustrar'. A iluminura (ilustração) tem um fim didascálico. Aquilo que os simples não pudessem entender através da escritura, deveria ser aprendido através das figuras [...] mas seria também o deleite visual dos incultos." (AZNAR, 1997, p.19)

Cerca de 1.700 anos depois, se realizarmos uma consulta ao verbete "vinheta" no dicionário ${ }^{2}$, encontraremos um sentido bastante próximo ao original: "pequena estampa de um livro, para ornato ou para explicação do texto; ornamento tipográfico, que se presta a numerosas combinações". É verdade que há muita diferença entre as primeiras vinhetas e as que vemos na televisão hoje em dia, mas estas ainda cumprem

2 FerReIRA, A. B. de H. Pequeno dicionário brasileiro da Língua Portuguesa. São Paulo: Civilização Brasileira, 1964. 
praticamente os mesmos papéis da iluminura da Idade Média: 1) funcionam como uma espécie de enfeite, preenchendo apenas os espaços vazios e 2) "iluminam”, relacionando-se com o conteúdo da mensagem transmitida.

Frisamos o termo praticamente porque em cada uma dessas funções-base o desenvolvimento de técnicas e instrumentos terminou por imprimir ligeiras alterações em seus significados. No primeiro caso, por exemplo, o caráter estético da vinheta foi incrementado ao longo dos séculos até chegar ao que conhecemos hoje como o design. E como sabemos, por trás do design há muito mais de estratégia do que de enfeite, simplesmente. No segundo caso, esse "estar relacionado com o conteúdo da mensagem" tem ido além da função ilustrativa (como acontecia no caso da iluminura). Hoje em dia, a vinheta é, ela própria, uma mensagem! Feitas essas considerações, podemos entender melhor a relação entre vinheta, marca e identidade visual.

\section{Vinheta: identificando a origem do produto}

Como vimos anteriormente, a apresentação da marca é capaz de representar garantia e qualidade para o telespectador. Exemplificaremos neste tópico o primeiro modo apontado para conseguir tal intento: a identificação da origem do produto. Para

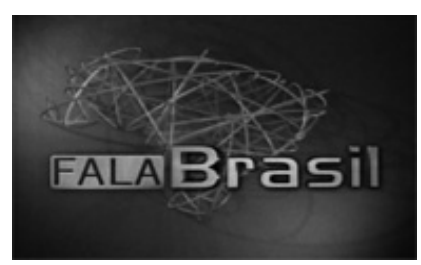

Figura 01

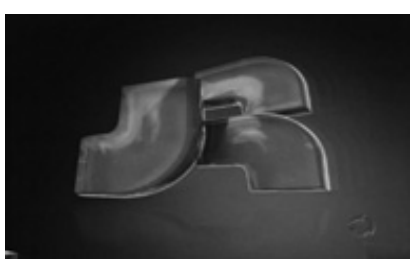

Figura 02

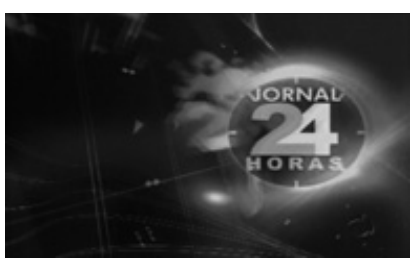

Figura 03

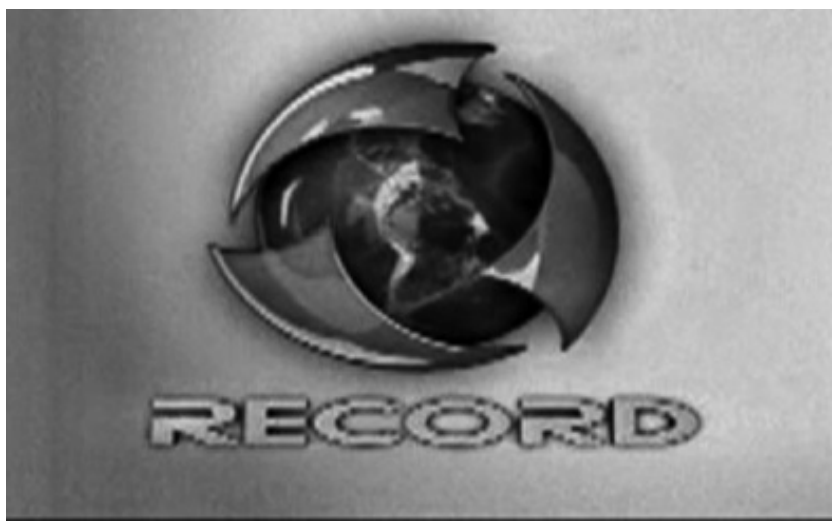

Figura 04 
isso, utilizamos as vinhetas dos telejornais "Fala Brasil", "Jornal da Record" e "Jornal 24 Horas”, transmitidos pela Rede Record de Televisão.

Retomando a definição do termo "marca", o processo de identificação de bens e serviços pode ser obtido por várias formas ${ }^{3}$ significantes: a) o nome da empresa, da instituição ou do produto em sua forma gráfica (escrita) ou sonora (falada), de modo a indicar instantaneamente a entidade ou a coisa representada; b) símbolo visual - figurativo ou emblemático; c) logotipo - representação gráfica do nome, em letras de traçado específico, fixo e característico; d) o conjunto desses símbolos, numa só composição gráfica, permanente e característica, constituída pelo nome, pelo símbolo e pelo logotipo.

Com relação às vinhetas, pode-se dizer que todos os recursos citados anteriormente são utilizados. Além disso, é possível observar em tais videografismos uma tentativa constante de aproximação com o próprio nome e estética da marca maior na qual estão inseridos: suas emissoras. Busca-se, portanto, gozar de um contrato anterior, instaurado pelas várias produções já realizadas, veiculadas e conhecidas do público. A qualidade observada, mesmo em outros segmentos - entretenimento, esporte, variedades - pode, então, ser revalidada ou mesmo intensificada no segmento noticioso e viceversa.

As cores das vinhetas de abertura dos telejornais da Rede Record de Televisão seguem o padrão do próprio logotipo da emissora: verde, azul e vermelho. Tanto nos programas como no próprio logo da Record, essas cores aparecem mescladas a outras: o verde com o amarelo, o azul com o laranja e o vermelho com o amarelo.

Isso indica que, além de se relacionar com o projeto editorial dos telejornais, a identidade televisual desses programas é construída também em relação ao padrão de plasticidade da própria emissora, a Rede Record de Televisão. O logotipo da emissora, por sua vez, nos remete à própria imagem televisiva, pois são essas as cores básicas dissociadas dentro de cada unidade pictórica - o pixel. Machado explica:

"se a imagem for codificada com informação de cor, a câmera de vídeo a divide em três componentes básicos (vermelho, verde e azul) por meio de um prisma divisor ou de espelhos dicróicos, de modo que a sua constituição em qualquer fase do processo mostrará sempre essa dissociação fundamental." (1997, p. 41)

Portanto, ao incorporarem as próprias cores do logotipo da emissora - verde, azul e vermelho - nas vinhetas, os telejornais cumprem a função de "marcar" o telespectador, reforçando a fonte do conteúdo a que está assistindo: a própria Rede Record de Televisão.

3 RABAÇA, C. A.; BARBOSA, G. G. Dicionário de comunicação. Rio de Janeiro: Elsevier, 2001. 


\section{Imagem e identidade: o conteúdo em questão}

O segundo aspecto que citamos relaciona-se com a questão do conteúdo. E, de fato, as vinhetas funcionam como uma espécie de convite ao telejornal, adiantando ao telespectador o que ele encontrará no programa. Vejamos, no exemplo do telejornal "Brasil Urgente", pertencente à Rede Bandeirantes de Televisão, como os elementos audiovisuais podem contribuir para reforçar aspectos da identidade dos noticiários, da própria prática jornalística em questão. Para isso, faremos a comparação do con-

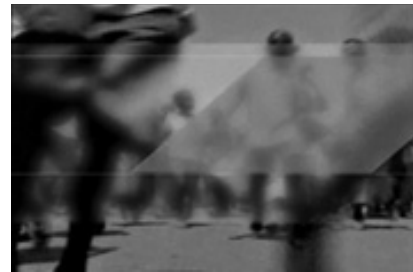

Figura 05

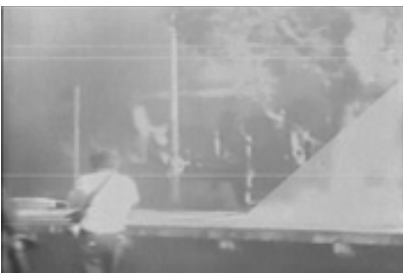

Figura 08

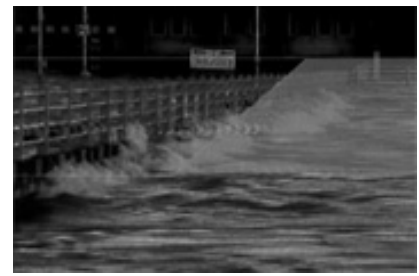

Figura 11

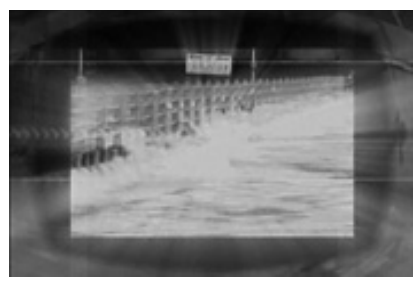

Figura 14

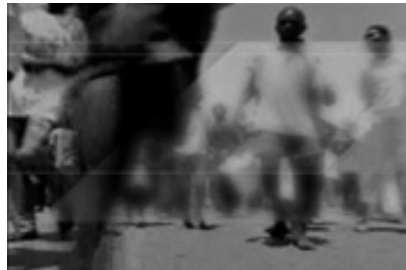

Figura 06

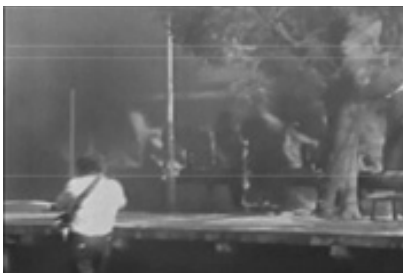

Figura 09

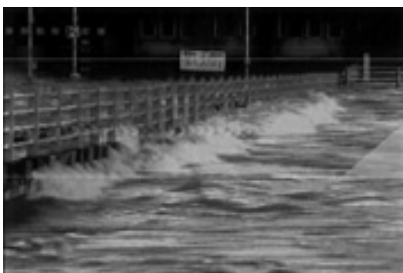

Figura 12

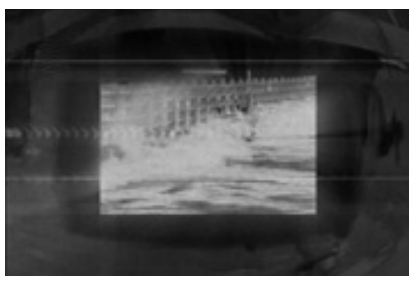

Figura 15

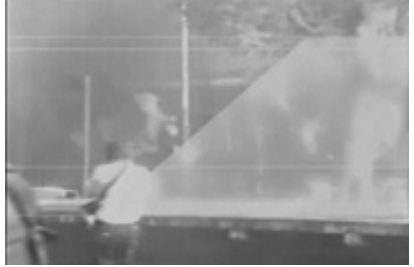

Figura 07

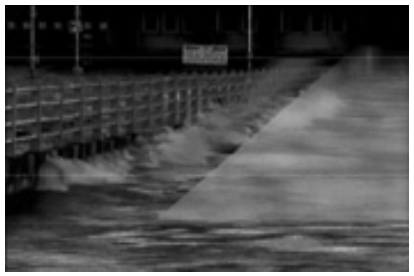

Figura 10

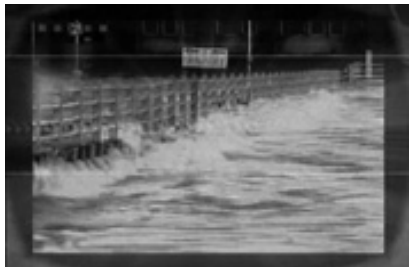

Figura 13

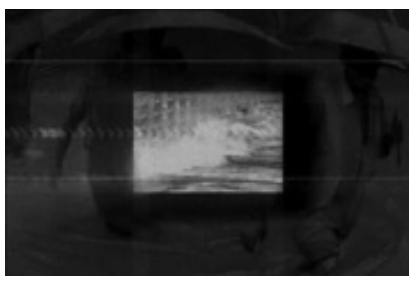

Figura 16 


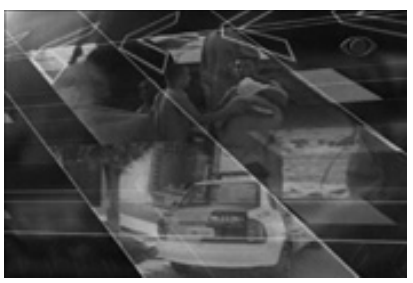

Figura 17

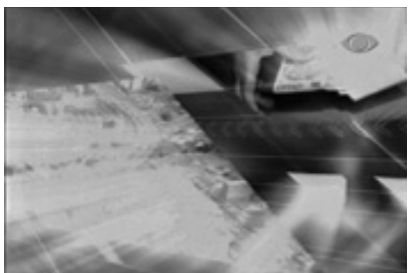

Figura 20

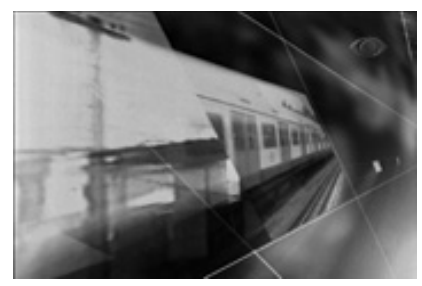

Figura 18

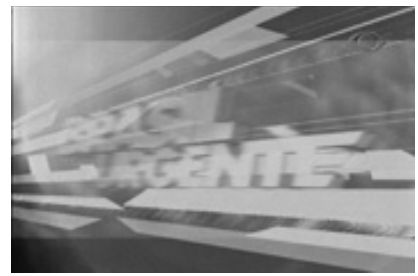

Figura 21

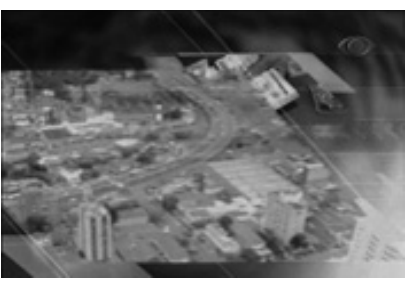

Figura 19

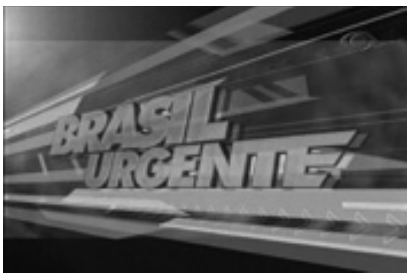

Figura 22

teúdo de auto-apresentação do telejornal, conforme apresentado no site ${ }^{4}$ da emissora, com o conteúdo da vinheta.

O que temos nessa vinheta são cenas da vida cotidiana - enchentes, aglomerações, cenas policiais, meios de transporte, incêndios, cidades - sendo captadas pelas lentes da mídia. Isso está de acordo com a proposta do telejornal, como lemos em sua apresentação na Internet: "José Luiz Datena dá prioridade aos temas locais e está muito perto do cidadão e seus problemas, com assuntos como segurança, saúde, trabalho e comportamento".

A presença da mídia é figurativizada pela presença de telas (ecrãs) no decorrer do vídeo e por formas geométricas que tomam contornos semelhantes a paralelogramos em boa parte da vinheta. Tais paralelogramos tomam forma de retângulos numa referência clara à televisão, como se pode observar nas figuras 13 a 16. E nesse sentido não se medem esforços, como podemos ler no site do telejornal: "a prestação de serviço tem atenção especial, com os repórteres sempre ao vivo, com um helicóptero, e duas motolinks, informando as condições do trânsito e relatando os flagrantes da cidade de São Paulo".

Assim, a vinheta consegue, por meio dos elementos audiovisuais, reforçar aspectos do projeto editorial e, portanto, da própria identidade do noticiário. Numa comparação com o que acontece no caso de outras indústrias, como a alimentícia, pode-se dizer que a vinheta funciona como uma espécie de "amostra grátis" do produto jornalístico. Se o telespectador gostar, permitirá que entre em sua casa.

4 www.band.com.br/brasilurgente/sobre.asp?ID=14. Acessado em 18 de maio de 2007. 


\section{Efetivando contratos: a busca pela audiência}

Neste terceiro item, abordaremos a efetivação de contratos por meio das vinhetas. Depois de conhecer a origem e o conteúdo do produto que pretende levar para casa, para que se efetue o "ato de compra", digamos assim, é necessário que o consumidor - ou telespectador, neste caso - acredite, deposite fé nas informações que recebe. É preciso que ele esteja convencido do valor do conteúdo em questão e, inclusive, de sua data de validade. Em jogo, o poder de persuasão da apresentação da marca. Vejamos como isso se dá na vinheta do "Jornal Nacional", da Rede Globo de Televisão.

Diferentemente do que acontece nas demais vinhetas analisadas, na abertura do "Jornal Nacional" os elementos de computação gráfica mesclam-se a elementos do nosso mundo natural. O logotipo "JN" do programa percorre o cenário e convida-nos, assim, a conhecer o estúdio de gravação no qual as notícias são produzidas. Uma espécie de "visite nossa cozinha!".

Essa breve passagem pela redação produz um efeito de proximidade entre o telejornal e o telespectador, pois rompe a barreira que separa a instância da enunciação (pro-

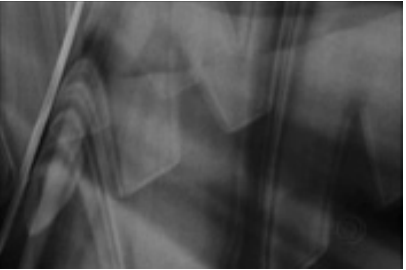

Figura 23

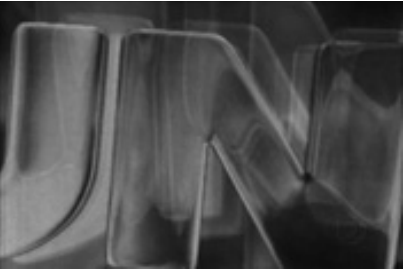

Figura 26

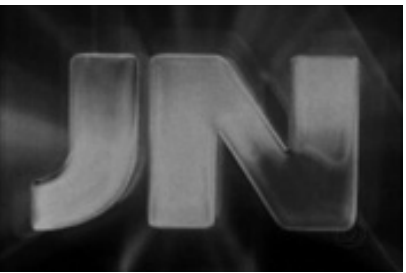

Figura 29

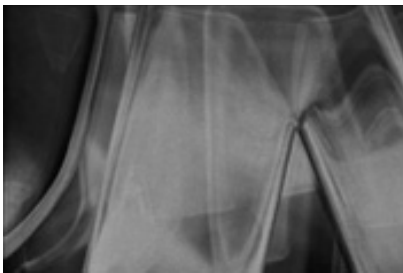

Figura 24

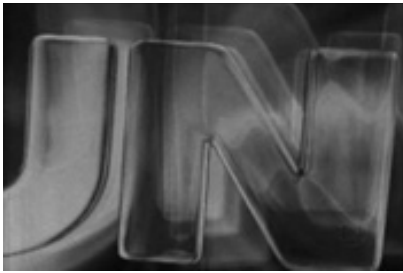

Figura 27

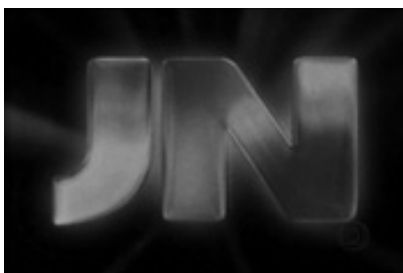

Figura 30

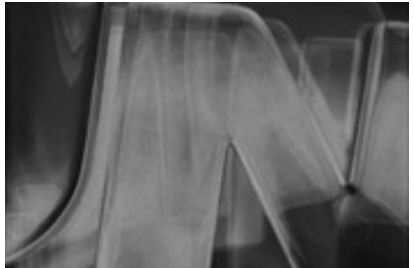

Figura 25

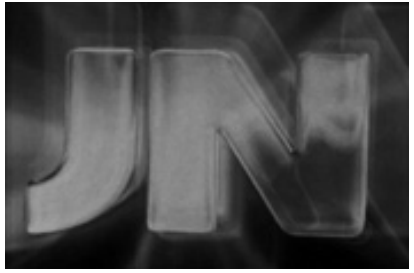

Figura 28

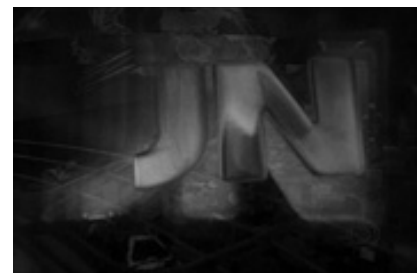

Figura 31 


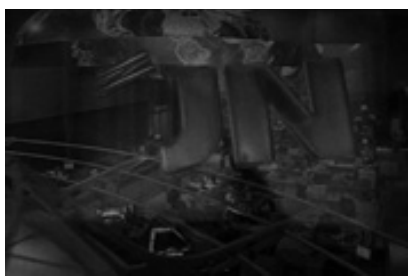

Figura 32

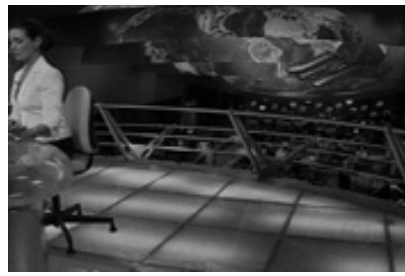

Figura 35

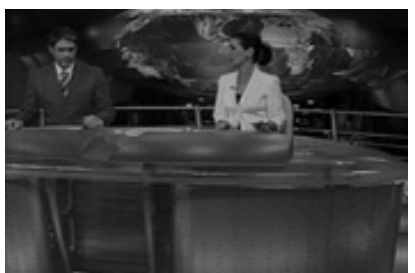

Figura 38

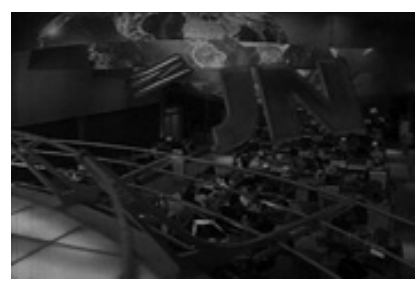

Figura 33

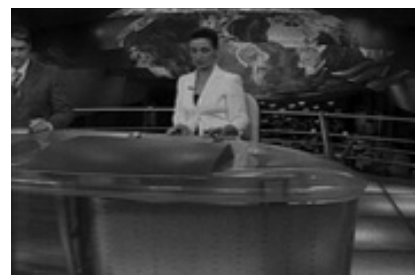

Figura 36

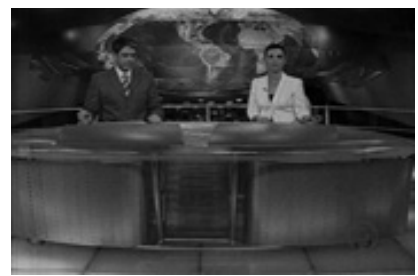

Figura 39

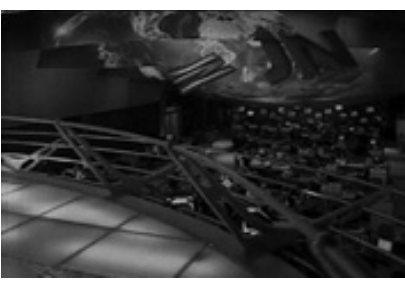

Figura 34

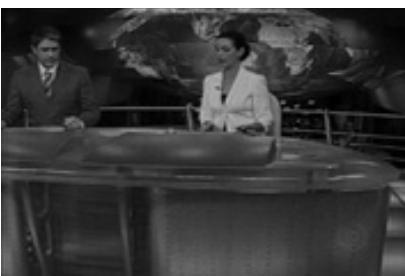

Figura 37

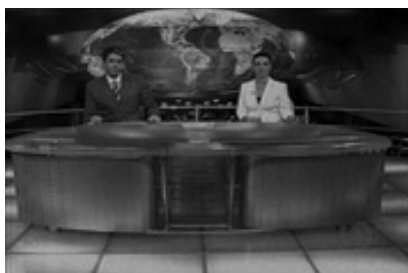

Figura 40

dução do noticiário) do enunciado (produto jornalístico) que chega aos lares de todo o Brasil. Um efeito de sentido que nos parece intencional, considerando a afirmação do site ${ }^{5}$ do programa, referente ao ano de 2000:

"O jornal sai do estúdio e passa a ser apresentado de dentro da redação. O telespectador pode ver a equipe envolvida na realização do telejornal, tanto na abertura quanto no inicio e fim de cada bloco. Um conceito que leva para dentro da casa do público a própria redação do Jornal Nacional."

Ao "mostrar suas entranhas", revelando os elementos de sua enunciação coletiva, o telejornal dá-se a conhecer intimamente: uma equipe, em trabalho constante, diante de computadores atentos ao que se passa no mundo. Elementos que incidem sobre o telespectador, inspirando sua confiança e crença.

Todo esse simulacro também confirma para o telespectador a promessa de vigilância do telejornal. Se esse efeito pode ser sentido pela presença de máquinas e profissionais trabalhando em busca da informação - que encenam também o tema da compe-

5 http://jornalnacional.globo.com/Jornalismo/JN/0,,3578,00.html. Acesso em 18 de maio de 2007. 
tência jornalística - nesse discurso em ato que se nos apresenta na vinheta, o telejornal fazendo-se ao mesmo tempo em que é exibido, garante-nos o efeito de sentido de atualidade - "nada lhe escapará".

As oposições / baixo/vs / alto / e / coletivo / vs / individual/ exploradas na vinheta não apenas apontam etapas distintas do fazer-telejornalístico (produção e apresentação, respectivamente) como atribui valores diferentes a elas e a seus executores. Assim, de todos os fatos que chegam à redação (coletivo/baixo), apenas os mais relevantes serão noticiados, selecionados pelo crivo dos jornalistas mais destacados (individual/alto).

Tal como as outras vinhetas, esse convite feito ao nosso olhar figurativiza temas caros ao telejornalismo -, intimidade, confiança, atualidade, competência jornalística, entre outros - capazes de estabelecer com o telespectador contratos de veridicção e fidúcia, necessários para conquistar sua adesão.

E na mesma medida em que contribuem para a firmação de contratos, as vinhetas contribuem para que as marcas (dos noticiários) se transformem no grande patrimônio das empresas. Nesse sentido, há ainda mais coisas envolvidas:

"É uma ilusão acreditar que um conceito de marca pode ser eficiente a partir de definições artificiais, criadas fora do contexto ideológico da empresa. Nenhum plano, por mais tecnicamente justificado, se sustenta sem considerar que toda marca nasce impregnada de um ideal. E ele será a essência do seu sucesso ou o mal congênito a comprometê-lo para sempre". (TARSITANO; NAVACINSK, 2004, p.231)

A questão do "ideal" de uma marca remete aos valores que estão em jogo entre as pessoas e os produtos, entre os fabricantes e o mercado. Antes de consumir os produtos - mesmo os jornalísticos - consumimos conceitos. No caso dos telejornais, levamos para a casa a idéia de verdade, atualidade e imparcialidade. Efeitos de sentido são disseminados por toda a produção dos noticiários - inclusive as vinhetas de abertura - para estabelecer não apenas a crença, mas, sobretudo, uma audiência cativa.

\section{Vinheta e televisão}

Nos tópicos anteriores discorremos sobre três funções básicas que as vinhetas cumprem no intuito de fortalecer o estabelecimento das marcas ou noticiários: identificação da origem do produto, apresentação do conteúdo e a efetivação de contratos com o telespectador. Mas, e quanto à televisão de modo geral? Que contribuição as vinhetas podem fornecer?

Sabe-se que um dos aspectos que constitui a estética da televisão é a auto-referencialidade, que diz respeito ao seu caráter metalingüístico. E isso por um motivo bastante simples: quem não anuncia não vende. É pela repetição que as marcas ficam gravadas em nossa mente! No caso da televisão, entenderemos isso melhor atentando para 
a tabela a seguir, que evidenciará como se dá essa auto-referencialidade, ou seja, quais são suas formas de aparição e com que freqüência ocorrem. Identificar tais formas de aparição é o primeiro passo para compreender as contribuições que a vinheta pode fornecer à televisão.

Também procuramos demonstrar por meio da tabela que a auto-referencialidade (por ser uma característica da televisão como um todo e não apenas de certos segmentos) está presente em todo tipo de programação. Assim, tivemos o cuidado de ilustrar nossa tabela com o break de diferentes tipos de programas (telejornais, novelas, seriados, revistas eletrônicas e outros) da televisão brasileira - escolhidos aleatoriamente - discriminados conforme as ocorrências encontradas:

- (C) Comerciais (de caráter nacional ou local)

- (I) Comerciais institucionais - relativos/financiados pela emissora ou afiliada

- (R) Comerciais referenciais - relativos à grade de programação

- (A) Comerciais de apoio à programação - marcas que financiam determinados programas

- (G) Comerciais de produtos do grupo - ex: Tele Sena, Som Livre etc.

- (P) Programas

- (_ Intervalo entre programas

Com relação ao aparecimento de vinhetas, encontramos:

- (1) Vinhetas de abertura - aparecem no início dos programas

- (2) Vinhetas de passagem - aparecem no início e/ou fim de cada bloco

- (3) Vinhetas de encerramento - aparecem ao término dos programas

- (4) Vinhetas institucionais - logo da emissora ou afiliada

Como pode ser observado nos dados da tabela, faz parte da estética da televisão a auto-referência. Se, de modo geral, considerarmos em cada emissora apenas os blocos que não contam como comerciais de apoio à programação ${ }^{6}$, a porcentagem de propaganda institucional ou referencial atinge os seguintes números: $58 \%$ na Globo, $60 \%$ na Bandeirantes, $47 \%$ no SBT, $82 \%$ na Fundação Padre Anchieta e 39\% na Record. Além disso, os comerciais referenciais e institucionais são os que prevalecem no caso de breaks entre programas. Sem dúvida, uma fórmula criada para manter o telespectador aprisionado na programação e estabelecer mais fortemente a marca da emissora e de seus produtos.

Nesse intuito, as vinhetas desempenham papel fundamental, já que é com base nelas que se dá a auto-referencialidade na televisão. De fato, toda propaganda institucional, bem como o comercial referencial, são realizados tendo como base uma vinheta de

6 Os comercias de apoio à programação constituem um tipo "híbrido", pois ao mesmo tempo em que destacam um produto ou marca independentemente da emissora, sua aparição está atrelada à programação televisiva, o que lhes confere uma aparição diferenciada, como veremos mais à frente. Por essas razões, optamos por estabelecer as porcentagens em blocos sem comerciais de apoio. 
Tabela $01^{*}$

\begin{tabular}{|c|c|c|c|}
\hline \multicolumn{4}{|c|}{ REDE GLOBO DE TELEVISÃO } \\
\hline & TELEJORNAL & NOVELA REVISTA & ELETRÔNICA \\
\hline $1^{\circ}$ bloco & P1RCCCRIAAAACR2P & P1RCCCCRGCCCR2P & 1P2RICCRCCCR2P \\
\hline $2^{\circ}$ bloco & P2RCCCRICCR2P & P2RCCRCRCCCIR2P & P2RCCIRCICCRA2P3 \\
\hline $3^{\circ}$ bloco & P2RCRCIAAAAACCR2P & P2RCCRRCGRA2P3 & \\
\hline- & RP1 & RARP & RCP \\
\hline \multicolumn{4}{|c|}{ REDE BANDEIRANTES DE TELEVISÃO } \\
\hline & PROG. FEMININO & PROG. DE ESPORTE & TELEJORNAL \\
\hline $1^{\circ}$ bloco & 1P2RCCCRCCCCR2P & 1P2CCICRCIRACCCRRAA2P & 1PI4CRAAA2P \\
\hline $2^{\circ}$ bloco & P2RCCCCCCCR2P & P2RCCCCCCRRA2P & P2RACCCCCRIAA4RA2P \\
\hline $3^{\circ}$ bloco & P2RCCCCRR4CCCR2P & P2RCCCCCCCIRAAA2P3 & P2RACCCIR2P \\
\hline$\ldots$ & P34P & RAAAIIRAA & P3RAAAI4RAP \\
\hline \multicolumn{4}{|c|}{ SISTEMA BRASILEIRO DE TELEVISÃO } \\
\hline & PROG. ENTREVISTA & TELEJORNAL & PROG. MUSICAL \\
\hline $1^{\circ}$ bloco & P1P2RACCCCCCCC2P & P1P2CCCCC2P & 1PRCCCCСCCC2P \\
\hline $2^{\circ}$ bloco & P2RAAAСССССССАA2P & P2CGCI2P & P2CCGGCCCCCI2P \\
\hline $3^{\circ}$ bloco & P2RACCCCG2P3 & P2GCGCG2P & P2RCGCGCCCCCC2P3 \\
\hline 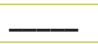 & R4P & RAAIR & RAAAAARIRAA \\
\hline \multicolumn{4}{|c|}{ FUNDAÇÃO PADRE ANCHIETA } \\
\hline & TELEJORNAL & REVISTA ELETRÔNICA & PROG. ENTREVISTA \\
\hline $1^{\circ}$ bloco & P1P2RAAARCCRCR42P & 1P2RAACCCCCR42P & 1P2RAACCCIR42P \\
\hline $2^{\circ}$ bloco & P2RACCRCCR42P & P2RAACCCCCR42P & P2RACRCIR42P \\
\hline $3^{\circ}$ bloco & P2RIRCR4P & P2CCCССCСIA RAA2P3 & P2RCRCIR42P3 \\
\hline- & 4RAARRAAAACR4 & 4RAAARCCRAA & 4RAAARR4 \\
\hline \multicolumn{4}{|c|}{ REDE RECORD DE TELEVISÃO } \\
\hline & TELEJORNAL & NOVELA & REALITY SHOW \\
\hline $1^{\circ}$ bloco & P1P2CCCRAAAARCCR2P & P1RCCCCCCRAACCCCCI2P & 1P2RCCCRRCCCCIR2P \\
\hline $2^{\circ}$ bloco & P2CIAAAAACCCC2P & P2RCCCССССC2P & P2RCRCRCCCCRAAAAAAA2P \\
\hline \multirow[t]{2}{*}{$3^{\circ}$ bloco } & P2CCRAAAARCI2P3 & PRCRAACCCCCC2P3 & 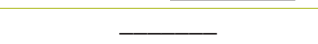 \\
\hline & $\overline{\text { RICRP }}$ & RIP & PRP \\
\hline
\end{tabular}

apresentação, seja a da própria emissora ou dos programas em questão - nos dois casos, as vinhetas podem aparecer integralmente ou apenas em parte.

Mas a auto-referência não é a única contribuição que as vinhetas oferecem para a televisão. Além disso, elas também aparecem de modo estratégico nos breaks comerciais, seguindo, em geral, a fórmula R2P (observe na tabela o final de cada intervalo), quer dizer, a seqüência de um comercial referencial, a vinheta de passagem e o programa. Esse "sinal de aviso" permite que o telespectador reconheça - quer pelo áudio da vinheta (sobretudo se estiver distante do ecrã), quer pelo visual - que o programa que 
está acompanhando entrará no ar em segundos, possibilitando, então, que o telespectador realize seus últimos ajustes e, desse modo, não perca parte da atração televisiva.

Nesse sentido, outro aspecto estratégico que merece ser levado em consideração tem a ver com os comerciais de apoio. Esse tipo de comercial funciona como uma espécie de resumo da propaganda e, em decorrência disso, seu tempo de exibição é menor. Dessa forma, uma seqüência de 3 a 4 comerciais de apoio e uma locução dinâmica imprimem um ritmo diferente ao break. Quando ocorre esse tipo de construção, o telespectador pressente - pelo hábito - que o intervalo terminará em breve.

Podemos destacar ainda outra contribuição. No desenvolvimento de alguns programas, tais como as revistas eletrônicas, a vinheta é responsável por marcar a organização dos assuntos abordados, fazendo a separação entre as sessões. A vinheta aparece estrategicamente, de modo a operacionalizar a fluição do tempo e dos conteúdos, já que a serialidade ${ }^{7}$ - conteúdos dispostos no tempo de modo seqüencial - é também uma das principais características da televisão analógica e, portanto, componente formador de sua identidade.

Assim, vemos a importância da utilização das vinhetas não apenas no âmbito da informação, mas da televisão como um todo, pela formação da estética da repetição, a função de "aviso" ao telespectador e administração do tempo e do conteúdo televisivo. No que diz respeito ao segmento informativo, vimos a contribuição das vinhetas quanto a identificar a origem do produto, apresentar seu conteúdo e efetivar contratos: na mira, o telespectador. A adesão da audiência. Afinal, sobretudo na telinha, tudo é uma questão de imagem.

\section{Referências}

AZNAR, S. C. Vinheta: do pergaminho ao vídeo. São Paulo: Arte \& Ciência, 1997.

FERREIRA, A. B. de H. Pequeno dicionário brasileiro da Língua Portuguesa. São Paulo: Civilização Brasileira, 1964.

MACHADO, A. A arte do vídeo. São Paulo: Ed. Brasiliense, 1997.

. A televisão levada a sério. São Paulo: Senac, 2000.

RABAÇA, C. A.; BARBOSA, G. G. Dicionário de comunicação. Rio de Janeiro: Elsevier, 2001.

SCHIAVONI, J. E. Telejornal: recortando a notícia. In: XXVIII Congresso Brasileiro de Ciências da Comunicação - Intercom, 2005, Rio de Janeiro. Anais, Rio de Janeiro: Sonopress Ind. Com. Fonográfica Ltda., 2005. 1 CD ROM.

TARSITANO, P. G.; NAVACINSK, S. D. G. Marca: patrimônio diferencial das empresas e diferencial dos produtos. In: MELO e outros (orgs.). Sociedade do conhecimento. Celacom: 2005.

WILLIAMS, R. Television: technology and cultural form. Glasgow: Fontana/Colins, 1979.

7 Sobre esse assunto, veja: WILLIAMS, R. Television: technology and cultural form. Glasgow: Fontana/Colins, 1979. Também: MACHADO, A. A televisão levada a sério. São Paulo: Senac, 2000.

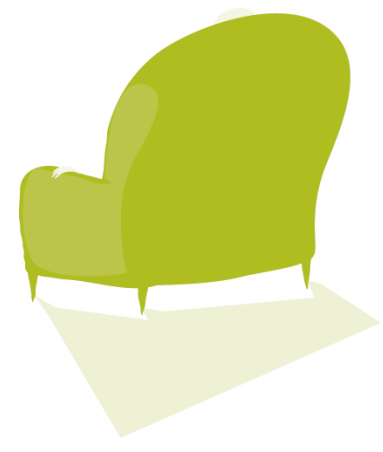

